The Rodier Method-Killing only Females.-Is slower and more difficult, but, it is efficacious in plenty or scarcity. It allows for long periods of neglect. It works in Nature's way.

You can only Conguer Nature by Obeying Her.

I regard rats as experimental subjects in tackling the Australian Rabbit Question. For the last twenty years rabbit poisoning has been obligatory throughout that continent-birds are killed, blow flies blacken festering heaps of corpses, and the rabbits swarm in ever denser multitudes. Every new settler increases the food supply, every year the rabbit press further north, into the areas still untainted. The rabbit pest is barely fifty years old; to-day it costs Australia $£ 25,000,000$; soon it will be $£ 50,000,000$ a year. What a life work to save $£ 1,000,000,000$ to the finest jewel in the British Empire.

Governments can be persuaded only by the plain logic of patent resultsthe more the workers, and wider the field, the quicker will come conviction. I am out to help Rodier to save Australia. I ask everyone's help by experiment of his system. It will cost you nothing but patience and goodwill. Rodier may be wrong, but if he be right, as I think he is, who could not be proud to have been even a humble helper in a cause so fraught with blessings to humanity.

\title{
Methods Employed for the Suppression of Rats in Royal Naval Ships and Establishments at Portsmouth.
}

By Surgeon-Commander R. J. Mackeown, O.B.E., M.B., D.P.H., Royal Navy, Naval Health Officer, Portsmouth Command (Member).

THE impetus given by the National Rat Weeks and by the Press has created a desire in Naval circles to reduce and keep in subjection the rat population.

The rat campaign was more called for at ports when ships were constantly arriving home from the East Indies and Eastern Mediterranean with troops and stores after the Armistice, bringing with them black rats, the noted plague carriers.

It was essential to destroy these pests at once in the ships and at the docks lest any of them getting on shore and, spreading inland, carried disease in their tracks. The methods used have been mainly trapping and poisoning. 
Trapping.-The following have been used:-Automatic French wire trap. Box or double-ended trap. Spring or break-back traps of various designs. Varnish traps. Figure of four. A South African snare.

Poisoning.-Trials have been made with rat cures-" Rat-Quit," " Londovus," and "Morisrite."

It is claimed for the first two that rats die in the open in search of water, and those that die under cover do not smell but dry up to the pelt, and that the success of the poisons was to be viewed not by the presence of dead rats, but by the absence of living ones.

Tame rats were purchased and wild rats were captured, and both were forcibly fed on these poisons, and their carcases were subjected to the following tests :- (a) Placed in a pail of salt water to represent a bilge or drain on board a ship. (b) Hung up in the open. (c) Enclosed in airtight boxes to represent inaccessible places, as under flooring and behind wainscotting.

As the result of this experience I can recommend the use of these poisons in the open, e.g., in stacks of timber, etc., but for indoor use I rely on traps.

Trials carried out with "Morisrite" have led me to the same conclusion.

From November, 1919, to 1st May, 1920, 774 black rats were caught in the Dockyard at Portsmouth, the greatest number for one week being 64 ; when it is considered that each pair of rats give rise to 200 at the end of one year, then these figures represent the prevention of over a quarter of a million.

When the rat population on board a ship is excessive the only effectual means of control is to fumigate the entire ship, holds and living quarters at the same time.

Fumigation is best carried out by sulphurous acid gas, generated by the Clayton apparatus, sulphume (liquid SO2), or by burning roll or rock sulphur in metal pots.

To be carried out efficiently, a party of men specially trained for this purpose is essential, and all efforts must be made to safeguard them by adopting the best methods and by providing suitable gas masks. 